\title{
Sociological Approaches to Translation Technology
}

\section{Document Version}

Accepted author manuscript

Link to publication record in Manchester Research Explorer

\section{Citation for published version (APA):}

Olohan, M. (2019). Sociological Approaches to Translation Technology. In M. O'Hagan (Ed.), The Routledge Handbook of Translation and Technology (pp. 384-397). Routledge.

\section{Published in:}

The Routledge Handbook of Translation and Technology

\section{Citing this paper}

Please note that where the full-text provided on Manchester Research Explorer is the Author Accepted Manuscript or Proof version this may differ from the final Published version. If citing, it is advised that you check and use the publisher's definitive version.

\section{General rights}

Copyright and moral rights for the publications made accessible in the Research Explorer are retained by the authors and/or other copyright owners and it is a condition of accessing publications that users recognise and abide by the legal requirements associated with these rights.

\section{Takedown policy}

If you believe that this document breaches copyright please refer to the University of Manchester's Takedown Procedures [http://man.ac.uk/04Y6Bo] or contact uml.scholarlycommunications@manchester.ac.uk providing relevant details, so we can investigate your claim.

\section{OPEN ACCESS}




\author{
Olohan, Maeve (2020) 'Sociological Approaches to Translation \\ Technology', in Minako O'Hagan, (ed.) Routledge Handbook of \\ Translation and Technology, London and New York: Routledge, 384-
}

397.

\section{Sociological Approaches to Translation Technology}

Maeve Olohan

While translation studies has become increasingly sociological in its methodological and conceptual focus, translation technology is only rarely at the forefront of such studies. This essay looks beyond Bourdieusian approaches to translation in fields of literary production to draw conceptual inspiration from the sociology of technology. By introducing key notions from the social construction of technology, and key concerns of recent studies on translation technologies, the essay identifies a potential trajectory for future sociological research on translation technology. As in other areas of social life, our understanding could be significantly enhanced by examining how translation technologies are inscribed with hegemonic values and by analyzing the socio-economic and political conditions and configurations that bring about the technologies and normalize them. The widespread deployment of machine translation technology also requires us to examine the contexts of translation technology design and use, in professional workplaces of translators but also beyond them. An emerging sociology of translation technology may, in turn, lead to revisions of traditional conceptualizations of translation, to account for the material, embodied and collective dimensions of both translation and technology, as well for their construction, meanings and impacts in specific cultural and socio-economic contexts.

Keywords: translation memory, machine translation, social construction of technology (SCOT), actornetwork theory

\section{Introduction}

Translation studies has engaged with sociological theories and research in various ways over recent decades. A set of concepts from Bourdieusian social theory has been given particular prominence when scholars have focused on translation as social practice and on the roles of translators and other human agents in that practice (Simeoni 1998; Gouanvic 2005; Inghilleri 2005; Simeoni 2007; Wolf and Fukari 2007; Wolf 2011; Vorderobermeier 2014; Hanna 2016). To a lesser extent, scholars have also drawn on actor-network theory (ANT) in studies of agents and networks (Buzelin 2005, 2006, 2007; Chesterman 2006; Hekkanen 2008; Jones 2009; Bogic 2010; Abdallah 2011; Aaltonen 
2013; Jansen and Wegener 2013; Buzelin 2014; Eardley-Weaver 2015; Buzelin and Baraldi 2016; Devaux 2017; O'Hagan 2017). However, relatively few sociology-informed studies of translation have devoted attention to the materials, tools or technologies involved in translation practice.

Against that backdrop, this essay is centred on 'sociological approaches to' translation technology, reflecting the fact that interest in what could eventually be referred to as 'the sociology of translation technology' is still in its infancy. Cronin's (2013) book on translation in the digital age provides a rich interpretation of some aspects of the evolution of translation technology. Other studies focusing on translation tools, examples of which are outlined below, use methods commonly employed in sociological research, without necessarily espousing a particular conceptualization or theory of technology. A small number of scholars have conducted sociologically informed studies of translation with tools and materials explicitly in focus (Risku and Windhager 2013; O'Hagan 2017; Ehrensberger-Dow and Massey 2017) or have explored the potential for specific conceptualizations of technology (Kenny 2017; Olohan 2011, 2017b) or materiality and mediality (Littau 2016a, 2016b) to direct our research on translation, past and present.

The discussion here draws conceptual inspiration principally from the established field of the sociology of technology, whose evolution is outlined briefly below. The essay thus first devotes space to a set of conceptual approaches that would be pertinent in dealing with translation technology from explicitly sociological perspectives but for which, as yet, only limited examples are found in the translation studies scholarship. Examples of existing, socially oriented research on translation technology are then discussed, noting some valuable contributions made and productive methods applied. The final section argues that the sociology of technology can usefully inform further research on translation technologies and can help to address questions that will be of increasing importance for translation scholars, pertaining to the design, deployment and impact of translation technologies, among translators but also in wider societal spheres..

The relative lack of theoretical reflection on tools and technologies in translation studies until recently has left specific gaps in scholarship but this essay can only address those gaps in broad terms and must inevitably leave numerous specific contexts unexplored. Interpreting practice and interpreting-specific technology are not discussed here, and more attention is given to translation activities in professional settings than in non-professional or volunteer settings. Moreover, since technology and translation are so inextricably entwined, there remains much scope for engagement between disciplines that think about translation in specific contexts and disciplines that think about technology in those same kinds of contexts. For example, feminist and postcolonial approaches to translation have evolved over several decades but no connections have yet been made between that work and the scholarship of feminist or postcolonial studies of technology (Harding 2009; Wajcman 2000).

\section{Social construction of technology - historical trajectory}

The evolution of interest in the sociology of technology is entangled with the development of the sociology of science and the discipline that became known as science and technology studies. Following World War II, positivist views of science were increasingly questioned and deconstructed by philosophers of science, including Feyerabend, Popper and Lakatos, and by historians of science such as Kuhn. Building on their seminal works and the sociological approach to science developed by Merton, a number of schools of thought developed in the 1970s and 1980s that set out to examine more closely the 'black box' of science from sociological perspectives. These groups were variously 
interested in the institutions, networks, people, apparatus and ideas of science, the circulation of scientific knowledge and practices, and the interactions between human agents and material objects, between science and society, etc. They shared some common goals and were certainly breaking new ground within sociology, but they also perceived distinctions between one another, for example in terms of the extent to which they sought explanation for scientific phenomena in the social arena, or the extent to which they considered science and society to be co-constructed. From an interest in providing sociological explanation for scientific knowledge, some of these scholars developed a parallel interest in explaining the black box of technology in similar ways, traced in more detail below. For a first-hand account of these developments, narrated by Pinch, one of the protagonists, see Tosoni and Pinch (2017).

A key moment in this sociological scholarship on technology was the publication of an essay by Pinch and collaborator Bijker in 1984, called 'The Social Construction of Facts and Artefacts: Or How the Sociology of Science and the Sociology of Technology Might Benefit Each Other'. This was the very first article on technology to be published in Social Studies of Science, an indication of how groundbreaking it was (Bijker and Pinch 2012: xiv). The authors argued for an integrated understanding of both science and technology as socially constructed, and introduced the approach that became known as SCOT, social construction of technology, which was illustrated with examples from the work of both scholars on solar physics and the development of the bicycle.

The starting point for Pinch and Bijker were the schools of thought that became known as the sociology of scientific knowledge (SSK) and that were being developed by researchers in Edinburgh and Bath in particular. SSK focused on the ideas of science rather than merely on its institutional organization. A key tenet of the SSK approach was that sociologists would be impartial to the knowledge claims they investigated, treating them all symmetrically, as socially constructed and therefore seeking social explanation for both claims that were regarded as false and those regarded as true. Extending this social constructivist line of thinking to technology, Pinch and Bijker (1984: 404) argued that 'science and technology are both socially constructed cultures and bring to bear whatever cultural resources are appropriate for the purposes at hand'. Economic accounts of technological development up to that point had tended to focus on innovation and they used the success of an artefact as the explanation of its development, thus eliding other aspects of its historical development. Pinch and Bijker proposed instead that it is precisely this success that needs to be explained, and that a sociology of technology needs to be able to account, symmetrically, for both successful and failed technologies.

Pinch and Bijker's (1984) extension of this research approach to technology was labelled the social construction of technology, or SCOT. The studies of science focused on empirical investigations of contemporary scientific developments, in particular of scientific controversies (1984: 409). Analogously, SCOT focuses on technological artefacts as developing multi-directionally, alternating between variation and selection. This means that SCOT moves away from the kind of linear narrative of technological development (sometimes unquestioningly equated with notions of progress) that often emerges from historical studies. SCOT aims instead to consider the variants of a technological artefact that succeed or endure and those that do not. These multiple possibilities are referred to as the technology's 'interpretative flexibility' (Pinch and Bijker 1984) and this is the first focus in a SCOT study. SCOT analysis of a particular technology therefore focuses on the problem addressed by the variants of the technology and the solutions it offered, with reference to the 'relevant social group' (ibid.) who are engaging with the technology. Relevant social groups may be institutions or organizations or groups of individuals. Members of a social group are 'relevant' in that they share a set of meanings for a particular artefact. Once identified by the SCOT analyst, the relevant social 
groups are described in detail. By tracing the relevant social groups and the potential conflicts between them, linked to variants of the technology and problems encountered and solved, the researcher follows the development of the different artefacts towards a degree of stabilization. As consensus emerges through social mechanisms, the interpretative flexibility is limited and 'closure' is achieved, thus eliminating the variation (ibid.). The mechanisms by which this closure is achieved, in the particular socio-cultural context, are also described in a SCOT study (ibid.: 409), and explanations are offered for the selection of one variant over another.

The example recounted by Pinch and Bijker (1984) is the story of how different versions of the bicycle developed, responding to the problems identified by different relevant social groups. Over a 19-year period, from 1879 to 1898 , a range of different bicycle designs were developed, related to different problems, solutions and relevant social groups (e.g. men who rode the unsafe highwheeled bicycle for sport; women who looked to cycling as a mode of transport; anti-cyclists who disrupted cyclists en route), before the artefact was stabilized in the 'safety bicycle' form that we recognize today.

Methodologically, Pinch and Bijker suggest that the interpretative flexibility in how artefacts are designed and culturally constructed and how consensus emerges can be demonstrated through interviews with technologists who are engaged in a technological controversy. The stabilization of the artefact, or the closure mechanisms, can also be studied through statements about the artefacts, including explanations, specifications and definitions that are offered in particular contexts and among more than one of the relevant social groups. Pinch and Bijker note that the closure of the technological controversy does not have to mean that the problems are solved but rather than the relevant social groups see the problem as being solved, and this may be performed via rhetorical moves and claims. In addition, problems may first be redefined before a solution is found, as an alternative means of achieving closure. The final stage of the SCOT analysis relates the technological artefact to its wider socio-cultural and socio-political situation. Here the norms and values of relevant social groups are regarded as being shaped by their socio-cultural and socio-political situations. These situations, in turn, shape the meaning given by the relevant social groups to the technology (ibid.: 428). By linking those different meanings to the artefacts through their development, the SCOT model operationalizes 'the relationship between the wider milieu and the actual content of technology' (ibid.: 429).

As the SCOT approach was being developed, other sociological approaches to the study of technology were also emerging, among them actor-network theory (ANT). ANT was proposed by Latour, Callon and Law in the 1980s as a materialist theory for understanding technoscience in terms of the networks formed by both human and nonhuman actors. These actors, human and nonhuman, act on the basis of their interests, and those interests are translated as they enrol other actors, form alliances and configure actor-networks. The actors are also characterized by the relations between the actors, and both actors and networks are uncertain and unfolding. As described by Law (1992, 381) in ANT terms, science is a 'process of "heterogeneous engineering" in which bits and pieces from the social, the technical, the conceptual and the textual are fitted together and so converted (or 'translated') into a set of equally heterogeneous scientific products.' Crucially, this description of patterned networks of heterogeneous materials is deemed just as applicable to the social world as a whole and to its actors as to the institution of science.

ANT has been used as a framework in a very large number of studies, in and beyond domains of science and technology, but including translation studies, as noted above. ANT studies rely on rich, qualitative, descriptive case studies focusing on specificities and heterogeneities (Law and Singleton $2013,500)$. Latour (1987) encouraged researchers to 'follow the actors', ethnographically seeking to 
understand how actors are shaped and assembled. More recently, ANT has been described as 'a sensibility to the materiality, relationality and uncertainty of practices, as a way of asking how it is that people and animals and objects get assembled in those practices, and as a way of mapping the relations of practices' (Law and Singleton 2013: 491).

Reflecting on the differences and similarities between SCOT and ANT, Pinch describes them as sharing a 'common enemy', that is 'a deterministic reading of technology' (Tosoni and Pinch 2017: 81). In taking a non-essentialist approach to technologies, the two frameworks treat the boundaries between the technological and the social as constructed by the actors, rather than as fixed or static. It was precisely the actors' juggling of technical and non-technical activities that was exciting in these new approaches as they evolved through the 1980s; an illustrative example cited is of Edison developing his work on resistance or lightbulbs but also going to Wall Street to raise finances for his companies (Bijker and Pinch 2012). Commenting on the now seminal status of their 1987 collected volume (Bijker, Hughes, and Pinch 2012), the editors describe the SCOT and ANT contributions as having had 'compelling stories to tell' and they stress the importance of this 'thick description' (Geertz 1973) in contributing empirically to their shared anti-deterministic aims (Bijker and Pinch 2012: xvii).

The shared constructivist approach to opening the black boxes of technology and society outweighed some of the specific differences between approaches. However, a key difference between SCOT research and ANT lies in the symmetry that ANT accords to human and non-human actors. SCOT analyses focus on relevant social groups and their dynamics, thus foregrounding human and epistemological issues. ANT analyses place equal emphasis on the role of non-human actors, without ontological distinction. There is thus a tension between the SCOT approach that seems to focus attention on how technology is constructed and its meanings represented by humans, on the one hand, and post-human approaches that decentre the human and take a performative perspective on how entities emerge (e.g. ANT or Pickering's (1995) 'mangle of practice'), on the other hand. The premises of each approach necessarily result in criticism of the other. Bijker and Pinch (2012: xxv) argue that, where non-human agency appears to be the focus, it is achieved only through human representation of that agency or human representation of the distinction between human and non-human agency. Latour, Pickering and others see their focus as being on the temporal emergence or becoming of human-machine couplings (Pickering 1995, 2008) or heterogenous assemblages (Latour 2005; Law and Singleton 2013) that are attended to in the real time of practice.

All of these constructivist approaches are, however, united in being at odds with conventional sociology, mostly because the latter distinguishes between human agency and the wider social structures that enable and constrain human action. These constructivist approaches, by contrast, do not draw the same clear-cut boundaries between structure and agency; structure is itself seen as being materially and technologically performed. Implications for research methodology arise from this stance; for example, Bijker and Pinch (2012) argues that an examination of social relationships alone will not help us in understanding how those relationships are mediated by technology and materiality. Bijker and Pinch assert that many technologies have been studied from a SCOT perspective, and that all technologies have the potential to be. That potential is, as yet, untapped for translation technologies. In the next section we examine the key questions and methodologies of recent sociologically oriented research on translation technologies, , with the aim of highlighting diverse and productive approaches and findings, but also of emphasizing the potential for further development of sociological perspectives and interpretations, drawing on the kinds of scholarship outlined above. 


\section{Translation technology research - sociological questions and methods}

Translation technology research with sociological dimensions has addressed questions about extent of use, features of interfaces and wider ergonomic issues, and perceptual, cognitive and emotive responses to technology. Researchers have employed a range of methods, including surveys, interviews, focus groups, observation, screen recording, video recording, eye tracking and discourse analysis, in both naturalistic and experimental settings.

Where researchers have aimed to find out what technological tools translators use, for what purposes, and how translators feel about tools more generally, they have typically used survey methods to elicit data which has been analyzed qualitatively or quantitatively, though seldom statistically. One of the most recent large surveys of translators in the UK, the UK Translator Survey (2017), focused on tools or technology in more than half of the questions posed. It aimed to find out what the most widely used tools are, how important specific tools were for translators in their work, whether they thought technology gave them a competitive edge and whether they predicted that technology would make human translators less important in the future. This can be seen as a recent example of the kinds of technology-focused surveys that have been deployed regularly since translation memory and other CAT tools became prevalent among translators (Lommel 2002, 2004; Fulford and Granell-Zafra 2005; Lagoudaki 2006; Dillon and Fraser 2006). In each case the surveys offer a snapshot of tool use among its targeted population, and potentially also some indicators of attitudes to technology. However, the surveys vary in their design and implementation, preventing systematic comparisons and observation of longitudinal trends.

Survey instruments have also been used effectively to research the ergonomics of the translation workplace, understood as its physical, cognitive and organizational aspects (Ehrensberger-Dow and O'Brien 2015; Ehrensberger-Dow et al. 2016). From a human-centred perspective, these analyses investigate, for example, the cognitive friction experienced by translators when they encounter resistance in their work and the scope for cognitive resources to be freed up if workflows and systems were optimized. Surveys have been supplemented by other data elicited in the workplace, including screen and video recordings, interviews and ergonomic assessments (Ehrensberger-Dow and Hunziker Heeb 2016; Ehrensberger-Dow and Massey 2017).

Although ergonomics extends to many aspects of the translation workplace, some studies have focused more specifically on the human-computer interface and the needs of translators or posteditors in relation to their user interface. For example, Moorkens and O'Brien $(2013,2017)$ use surveys and then interviews to address questions related to interface design for post-editing. One of their conclusions would be highly relevant for a SCOT analysis of the interaction between designers and users of translation technology. Moorkens and O'Brien (2017) note that design is usually not user-centred; user feedback on design issues is either not elicited or is elicited but not used. They also argue that more input is required from experts in human-computer interaction to tackle longstanding problems with TM interfaces. Teixeira and O'Brien (2017) extend their analysis to data derived from keystroke logging, screen recording and eye-tracking, alongside retrospective interviews, in their investigation of how translators allocate visual attention and switch between tools and tasks as they perform translation and terminology research.

Also prompted and framed by questions of ergonomics, Cadwell et al.'s (2016) study examines attitudes to the adoption of machine translation (MT) by translators in the European Commission's Directorate-General for Translation (DGT). In this study a focus group methodology is chosen for its usefulness in eliciting information about both shared and individual perspectives and in allowing researchers to probe the reasons behind translators' views and preferences. Participants were 
encouraged to discuss features of their work practices, including factors such as volumes and deadlines, the lack of stability of source texts, and the specific responsibilities felt by DGT translators when producing legislative texts. These factors helped to explain, to some extent, translators' motivations to adopt or reject machine translation, but their decisions could be further rationalized by considering the wider socio-cultural context of these work practices, beyond the activities of individual translators at their workstations. The researchers conclude that factors such as job security, recognition within the larger institutional context, and the relative freedom accorded to DGT translators in organizing their work and in choosing tools also played a role in adoption or nonadoption of MT. In the light of this finding, they plan to make comparisons with commercial settings, where translators' experiences of job security, status and professional autonomy may be rather different from those of their institutional counterparts.

From the late 1970s onwards, science scholars began to apply ethnomethodological approaches in their investigations of how science was done in laboratories and other sites (Latour and Woolgar 1979; Knorr Cetina 1981; Lynch 1985; Traweek 1988). Likewise, from the early 2000s, small numbers of translation scholars have turned to methods that are characteristic of ethnographic research, to study translation as performed in the workplace and at other sites. Seminal studies combined workplace observations with interview data and artefact analysis to shed light on professional translation practices in a variety of settings, including the Finnish translation service of the European Union (Koskinen 2008), an Austrian language service provider (Risku 2004, 2009) and the Quebec literary publishing scene (Buzelin 2006). More recent settings for workplace observations include additional language service providers (LSPs), localization and transcreation companies, and institutional translation departments.

While ethnographic methods are well established in some other domains of workplace studies and the sociology of work, they are relatively new for translation scholars and they offer much scope for further application and exploitation in their various forms. The majority of workplace observations have been by one or more translation researchers who are granted access to one or more workplace sites in which translation or translation project management are being performed. Workplace observations have often been supplemented by interviews with participants, during or after the periods of observation, and analyses of texts and other artefacts from the field site. Research has focused on a range of questions and issues pertaining to work practices, interactions and relations between actors. Analyses have given varying degrees of attention to the materials, including technologies, that are considered to have been constructed, used, mediated or enacted in work practices, depending on conceptual perspectives. Examples of such studies, in addition to those discussed explicitly below, include Abdallah (2010, 2011), Pedersen (2017), Olohan and Davitti (2017), Olohan (2017a) and Kolb (2017).

Studies using other forms of workplace observation include Kuznik and Verd's (2010) re-analysis of quantitative self-observation data collected in a Polish translation agency between 1999 and 2000. The translators' own records of their daily activities revealed the wide variety of interactions between translators and other human and non-human actors, the range of different elements of translation assignments and their different stages, and the disturbances to productive work that translators experience. In another methodological variation, Kuznik (2016) was employed by a machine-manufacturing company to define the job profile for the company's 'in-house translator', whose work also included contributions to production processes and sales activities through various forms of linguistic mediation. The heterogenous work processes of the incumbent were studied from this internal vantage point using a combination of interviews, workplace observations, artefacts produced in the workplace (e.g. email exchanges) and self-observation protocols produced by the 
translator. A further variation on ethnographic studies, autoethnography, is relatively rare in translation, although Hurd (2010) offers an example for medical translation and Hokkanen (2017) for church interpreting. Koskinen (2008: 51-55), as a former member of the Finnish translator community she studies, offers useful reflection on the roles and identities of the researcher, and on the interactions between retrospection and observation.

A final methodological approach to mention here is the ongoing work of the Poettrio Experiment project (https://poettrioexperiment.com/) which is studying collaborations between a poet who has written a poem in a source language, a poet who writes in a target language and a language advisor who is an expert in both languages. The face-to-face encounters of several such triadic configurations as they collaborate to produce poetry translations in the target language are videorecorded and offer a rich source of data on collective translation processes.

The early ethnographic accounts of workplace practices focused on diverse aspects of translation practice, including the application of institutional rules, norms and beliefs in the EU context (Koskinen 2008) but were not necessarily focused on technology or tools. Risku's (2004) study, now in its third edition, was one of the first to consider the materially mediated cooperation and coordination of translation production networks. As part of her analysis of situated and extended cognition, Risku (2009) devotes attention to a wide range of artefacts that figured in the LSP workflow. These include physical and virtual objects used in communication - telephone, fax, post, email - and objects used in the course of document production, namely software applications for word processing, file conversion, translation memory, terminology management, internet research, as well as dictionaries, physical notes and lists. Artefacts used for administrative purposes included physical job lists, files, purchase orders, checklists and electronic databases and file archives, with archival needs met by various backup and storage systems. Risku and colleagues have continued to attend to the materially mediated processes and situated cognition of translation (Risku and Windhager 2013; Risku 2016; Risku, Rogl, and Milosevic 2017).

As the range of technologies used in the translation workplace has grown, workplace studies have tended to focus specific attention on translation memory (TM) and machine translation (MT) technologies. LeBlanc $(2013,2017)$, for example, conducts extended periods of observation in the workplace to examine the use of TMs. Where TM use has been enforced by LSPs as productivity measures, he focuses on translators' negative reactions as they perceive a loss of autonomy and a weakening of their professional status through this industrialization of translation (LeBlanc 2017). LeBlanc does not draw on a SCOT framework but his study highlights the significance of studying the perceived meanings and purposes of technologies among relevant social groups, as decisions are made and technologies are implemented in the workplace.

Contextual enquiry has been seen as a more practical method to implement in the translation workplace than lengthy periods of observation. This is a method developed by Beyer and Holtzblatt (1997) as a means for product designers to gather data from a small number of participants in the field to gain a better understanding of work practices related to a particular design issue (ibid.:37) and thereby to uncover commonalities among users. The method consists of one-to-one interviews in the workplace, typically over a two or three-hour period, in which the researcher observes people doing their own work, talks to them about their activities, seeking to uncover unarticulated aspects of work, learning about participants' past experiences, and developing a shared understanding of the aspects of the work that are relevant to the designer's purpose. Insights gained through contextual interviews of this kind are taken back to the design team to help them to address the design problem. Beyer and Holtzblatt, on the one hand, consider the interviewer as assuming the role of an apprentice learning a task from a master in the field, exposed to ongoing experience and 
concrete data rather than summaries $(1997 ; 47)$. However, in contrast to the apprentice-master model, the interviewer helps the participants to articulate their work experience by alternating between watching and probing (1997: 53), and so the relationship is more fittingly described as a partnership in which both participants are sensitized to work structures and design issues, in which the interviewer tests out their interpretations of what is happening.

Désilets et al. (2009) use contextual enquiry to study how translators employ expert judgement in selecting and using various resources during translation. Karamanis et al. (2011) examine aspects of localization processes in LSPs, focusing on collaboration and trust between translators, comparing 'relatively seamless' flow of work between in-house staff with more problematic relationships between in-house staff and remote translators. Karamanis et al. (2011) were able to use observations about TM use in particular to pinpoint a relative lack of trust in freelance translators who are not on site and do not participate in co-located team members' collaborative efforts to maintain quality. Communications with remote freelancers (and clients) were much more constrained than interactions on site. A similar level of mistrust is shown towards internet resources and newly introduced MT, which failed to impose too much rigidity on work practices.

Studies that foreground technology but in translation settings other than the traditional workplace are growing, some drawing on methods of netnography (Kozinets 2010,2015) and focusing on translation crowdsourcing, fansubbing communities and other non-professional translation settings. These are not further elaborated on here but O'Hagan's case study of Facebook's translation crowdsourcing provides a useful example of how actor-network theory can help to address research questions about translator autonomy and trust in the technology-mediated translation network. O'Hagan argues that the establishment of the crowdsourcing network creates an illusion of autonomy but the network members are given little or no control over the technology and the way it is set up to control their translation tasks and translation quality. Rather, translators are required to adapt themselves to the technology which is controlled by Facebook through top-down processes and structures. As other researchers have done, O'Hagan calls for more engagement between translators and technology developers.

Finally, a few studies have used discourse-analytical approaches to examine how meanings of translation technologies are constructed. Mihalache (2008), for example, analyzes discourses of a leading translation technology provider as it assigns meanings to translation-related practices and makes decisions based on the representations it constructs and the strategic interests it seeks to fulfil. She also extends this analysis to reflections and opinions on translation technology as represented in translators' online communities (Mihalache 2009). Koskinen and Ruokonen (2017) offer a novel discursive study of translators' emotional responses to technology. Using a method adopted from usability studies, they elicit love letters and break-up letters written by translators to a tool of their choice and subsequently conduct a qualitative analysis of the narratives produced. Koskinen and Ruokonen conclude that translators are not averse to technology, as was claimed in some of the earlier survey-based research. Through their usability-focused analyses, the researchers link positive affect most strongly to efficiency or user satisfaction. Negative affect is also linked to efficiency (i.e. lack of it) but more strongly to system errors. This narrative analysis offers insights into usability but is also a rare example of research that seeks to focus on affect or emotional response. 


\section{Towards a sociology of translation technology}

By considering the conceptual approaches above and a selection of existing studies of translation technologies, this essay aimed to illustrate that technology is being accorded attention by translation scholars but there is still much scope to develop our sociological approaches, both conceptually and empirically. In particular, it is argued that translation scholarship thus far has seldom addressed questions about the construction of meanings in relation to translation technologies, and the ways in which certain relevant social groups and their values and interests dominate in decisions relating to design and implementation. Such a research focus could expose the illusions of technological obligation or determinism that pervade much discourse on translation technology and could lay bare the specific roles of the full range of relevant social groups who interact with translation technology in professional spheres.

By describing the entanglements of relevant social groups, constructivist studies of technology have tended to focus more on local interactions between actors and their negotiations of meaning than on macro-institutional perspectives related to power distributions and power inequalities (Leonardi and Barley 2010). However, as Feenberg $(1992,1999)$ illustrates, such constructivist analyses can be fruitfully combined with critical theory of technology to expose the mechanisms by which unequal power distributions are perpetuated by technological decisions. This approach, which is both critical and empirically oriented, can dispel the myths that technologies are neutral or innocent (Hornborg 2014) and that we must resort to technological solutions for social problems (Morozov 2013). As in other areas of social life, our understanding of translation technology could be significantly enhanced by examining how technologies are inscribed with hegemonic values and by analyzing the socio-economic and political conditions and configurations that bring about the technologies and normalize them. That research will require us to continue to explore the contexts of translation technology design and use, in professional workplaces of translators but also increasingly beyond them, as the deployment of machine translation technology becomes ubiquitous. Conceptually, this work is likely to benefit from insights from disciplines such as the sociology of technology and the sociology of work, among others. It is also likely to lead to revisions of many of the traditional conceptualizations of translation, as we seek to account more fully for the material, embodied and collective dimensions of both translation and technology, as well for the hegemonic domination that they propagate or disrupt in specific cultural and socio-economic contexts.

\section{References}

Aaltonen, S. (2013) 'Theatre Translation as Performance', Target. International Journal of Translation Studies 25(3): 385-406.

Abdallah, K. (2010) 'Translators' Agency in Production Networks', in T. Kinnunen and K. Koskinen (eds) Translators' Agency, Tampere: Tampere University Press, 11-46. Available online: http://tampub.uta.fi/handle/10024/65639 [last access 9 April 2018].

Abdallah, K. (2011) 'Quality Problems in AVT Production Networks: Reconstructing an Actor-Network in the Subtitling Industry', in A. Serban, A. Matamala and J.M. Lavaur (eds) Audiovisual Translation in Close-Up: Practical and Theoretical Approaches, Bern: Peter Lang, 173-86.

Beyer, H. and K. Holtzblatt (1997) Contextual Design: Defining Customer-Centered Systems, San Francisco: Morgan Kaufmann. 
Bijker, W.E., T.P. Hughes and T. Pinch (eds) (2012) The Social Construction of Technological Systems: New Directions in the Sociology and History of Technology, 2nd ed., Cambridge, MA: The MIT Press.

Bijker, W.E. and T. Pinch (2012) 'Preface to the Anniversary Edition', in W.E. Bijker, T.P. Hughes and T. Pinch (eds) The Social Construction of Technological Systems, 2nd ed., Cambridge, MA: The MIT Press, xi-xxxiv.

Bogic, A. (2010) 'Uncovering the Hidden Actors with the Help of Latour: The "Making" of The Second Sex', MonTI. Monografías de Traducción e Interpretación(2): 173-92.

Buzelin, H. (2005) 'Unexpected Allies: How Latour's Network Theory Could Complement Bourdieusian Analyses in Translation Studies', The Translator 11(2): 193-218.

Buzelin, H. (2006) 'Independent Publisher in the Networks of Translation', TTR: Traduction, Terminologie, Rédaction 19(1): 135-73.

Buzelin, H. (2007) 'Translations "in the Making"', in M. Wolf and A. Fukari (eds) Constructing a Sociology of Translation, Amsterdam \& Philadelphia: John Benjamins, 135-69

Buzelin, H. (2014) 'Translating the American Textbook', Translation Studies 7(3): 315-34.

Buzelin, H. and C. Baraldi (2016) 'Sociology and Translation Studies: Two Disciplines Meeting', in Y. Gambier and L. van Doorslaer (eds) Border Crossings: Translation Studies and Other Disciplines, Amsterdam \& Philadelphia: John Benjamins, 117-39.

Chesterman, A. (2006) 'Questions in the Sociology of Translation', in J.F. Duarte, A. Assis Rosa and T. Seruya (eds), Translation Studies at the Interface of Disciplines, Amsterdam \& Philadelphia: John Benjamins, 9-28.

Cronin, M. (2013) Translation in the Digital Age, London \& New York: Routledge.

Désilets, A., C. Melançon, G. Patenaude and L. Brunette (2009) 'How Translators Use Tools and Resources to Resolve Translation Problems: An Ethnographic Study', Proceedings of Machine Translation Summit XII, Ontario, Canada. Available online: http://www.mt-archive.info/MTS2009-Desilets-2.pdf [last access 9 April 2018].

Devaux, J. (2017) Technologies in Interpreter-Mediated Criminal Court Hearings: An Actor-Network Theory Account of the Interpreter's Perception of her Role-Space, PhD thesis, The University of Salford. Available online: https://usir.salford.ac.uk/43417/ [last access 9 April 2018].

Dillon, S. and J. Fraser (2006) 'Translators and TM: An Investigation of Translators' Perceptions of Translation Memory Adoption', Machine Translation 20(2): 67-79.

Eardley-Weaver, S. (2015) 'Opening Eyes to Opera: The Process of Translation for Blind and Partially Sighted Audiences', in M. Ehrensberger-Dow, B. Englund Dimitrova, S. Hubscher-Davidson and U. Norberg (eds) Describing Cognitive Processes in Translation: Acts and Events, Amsterdam \& Philadelphia: John Benjamins, pp. 125-45.

Ehrensberger-Dow, M. and A. Hunziker Heeb (2016) 'Investigating the Ergonomics of a Technologized Translation Workplace', in R. Muñoz Martín (ed.) Reembedding Translation Process Research, Amsterdam \& Philadelphia: John Benjamins, 69-88.

Ehrensberger-Dow, M., A. Hunziker Heeb, G. Massey, U. Meidert, S. Neumann and H. Becker (2016) 'An International Survey of the Ergonomics of Professional Translation', ILCEA. Revue de I'Institut des Langues et Cultures d'Europe, Amérique, Afrique, Asie et Australie 27. Available online : http://ilcea.revues.org/4004 [last access 9 April 2018].

Ehrensberger-Dow, M. and G. Massey (2017) 'Socio-Technical Issues in Professional Translation Practice', Translation Spaces 6(1): 104-21. 
Ehrensberger-Dow, M. and S. O'Brien (2015) 'Ergonomics of the Translation Workplace: Potential for Cognitive Friction', Translation Spaces 4(1): 98-118.

Feenberg, A. (1992) 'Subversive Rationalization: Technology, Power, and Democracy', Inquiry 35(34): 301-22.

Feenberg, A. (1999) Questioning Technology, London \& New York: Routledge.

Fulford, H. and J. Granell-Zafra (2005) 'Translation and Technology: A Study of UK Freelance Translators', JoSTrans - The Journal of Specialised Translation 4: 2-17. Available online: http://www.jostrans.org/issue04/art fulford zafra.php [last access 9 April 2018].

Geertz, C. (1973) The Interpretation of Cultures, New York: Basic Books.

Gouanvic, J.-M. (2005) 'A Bourdieusian Theory of Translation, or the Coincidence of Practical Instances: Field, "Habitus", Capital and "Illusio"', The Translator 11(2): 147-66.

Hanna, S. (2016) Bourdieu in Translation Studies: The Socio-Cultural Dynamics of Shakespeare Translation in Egypt, New York: Routledge.

Harding, S. (2009) 'Postcolonial and Feminist Philosophies of Science and Technology: Convergences and Dissonances', Postcolonial Studies 12(4): 401-21.

Hekkanen, R. (2008) 'Fields, Networks and Finnish Prose: A Comparison of Bourdieusian Field Theory and Actor-Network Theory in Translation Sociology', Selected Papers of the CETRA Research Seminar in Translation Studies (Vol. 2009).

Hokkanen, S. (2017) 'Experiencing the Interpreter's Role: Emotions of Involvement and Detachment in Simultaneous Church Interpreting', Translation Spaces 6(1): 62-78.

Hornborg, A. (2014) 'Technology as Fetish: Marx, Latour, and the Cultural Foundations of Capitalism', Theory, Culture \& Society 31(4): 119-40.

Hurd, E. (2010) 'Confessions of Belonging: My Emotional Journey as Medical Translator', Qualitative Inquiry 16(10): 783-91.

Inghilleri, M. (ed.) (2005) The Translator, Special Issue Bourdieu and the Sociology of Translation and Interpreting, Vol. 11(2).

Jansen, H. and A. Wegener (2013) 'Multiple Translatorship', in H. Jansen and A. Wegener (eds) Authorial and Editorial Voices in Translation 1: Collaborative Relationships between Authors, Translators, and Performers, Toronto: Éditions québécoises de l'œuvre.

Jones, F.R. (2009) 'Embassy Networks: Translating Post-War Bosnian Poetry into English', in J. Milton and P. Bandia (eds) Agents of Translation. Amsterdam \& Philadelphia: John Benjamins, 30126.

Karamanis, N., S. Luz and G. Doherty (2011) 'Translation Practice in the Workplace: Contextual Analysis and Implications for Machine Translation', Machine Translation 25(1): 35-52.

Kenny, D. (2017) 'Introduction', in D. Kenny, (ed.) Human Issues in Translation Technology, London \& New York: Routledge, 1-7.

Knorr Cetina, K.D. (1981) The Manufacture of Knowledge: An Essay on the Constructivist and Contextual Nature of Science, Oxford: Pergamon.

Kolb, W. (2017) “'It Was on My Mind All Day"', Translation Spaces 6(1): 27-43.

Koskinen, K. (2008) Translating Institutions: An Ethnographic Study of EU Translation, Manchester: St Jerome.

Koskinen, K. and M. Ruokonen (2017) 'Love Letters or Hate Mail? Translators' Technology Acceptance in the Light of Their Emotional Narratives', in D. Kenny (ed.) Human Issues in Translation Technology, London \& New York: Routledge, 8-24.

Kozinets, R.V. (2010) Netnography: Doing Ethnographic Research Online, London: SAGE. 
Kozinets, R.V. (2015) Netnography: Redefined, London: SAGE.

Kuznik, A. (2016) 'Work Content of In-House Translators in Small and Medium-Sized Industrial Enterprises: Observing Real Work Situations', JoSTrans - The Journal of Specialised Translation 25: 213-31. Available online: http://www.jostrans.org/issue25/art kuznik.pdf [last access 9 April 2018].

Kuznik, A. and J.M. Verd (2010) 'Investigating Real Work Situations in Translation Agencies: Work Content and Its Components', Hermes 44: 25-43.

Lagoudaki, E. (2006) Translation Memory Systems: Enlightening Users' Perspective, London: Imperial College London.

Latour, B. (1987) Science in Action: How to Follow Scientists and Engineers through Society, Milton Keynes: Open University Press.

Latour, B. (2005) Reassembling the Social: An Introduction to Actor-Network-Theory, Oxford: Oxford University Press.

Latour, B. and S. Woolgar (1979) Laboratory Life: The Social Construction of Scientific Facts., Beverly Hills: Sage.

Law, J. (1992) 'Notes on the Theory of the Actor-Network: Ordering, Strategy, and Heterogeneity', Systemic Practice and Action Research 5(4): 379-93.

Law, J. and V. Singleton (2013) 'ANT and Politics: Working in and on the World', Qualitative Sociology 36(4): 485-502.

LeBlanc, M. (2013) 'Translators on Translation Memory (TM): Results of an Ethnographic Study in Three Translation Services and Agencies', Translation \& Interpreting 5(2): 1-13.

LeBlanc, M. (2017) “I Can't Get No Satisfaction!” Should We Blame Translation Technologies or Shifting Business Practices?', in D. Kenny (ed.) Human Issues in Translation Technology. London \& New York: Routledge, 45-62.

Leonardi, P.M. and S.R. Barley (2010) 'What's Under Construction Here? Social Action, Materiality, and Power in Constructivist Studies of Technology and Organizing', The Academy of Management Annals 4(1): 1-51.

Littau, K. (2016a) 'Translation and the Materialities of Communication', Translation Studies 9(1): 8296.

Littau, K. (2016b) 'Translation's Histories and Digital Futures', International Journal of Communication 10: 907-28.

Lommel, A. (2002) LISA 2002 Translation Memory Survey, Romainmotier: Localization Industry Standards Association.

Lommel, A. (2004) LISA 2004 Translation Memory Survey, Romainmotier: Localization Industry Standards Association.

Lynch, M. (1985) Art and Artifact in Laboratory Science: A Study of Shop Work and Shop Talk in a Research Laboratory, London: Routledge \& Kegan Paul.

Mihalache, I. (2008) 'Community Experience and Expertise: Translators, Technologies and Electronic Networks of Practice', Translation Studies 1(1): 55-72.

Mihalache, I. (2009) 'Social and Economic Actors in the Evaluation of Translation Technologies: Creating Meaning and Value When Designing, Developing and Using Translation Technologies', Linguistica Antverpiensia 8: 159-77.

Moorkens, J. and S. O'Brien (2013) 'Assessing User Interface Needs of Post-Editors of Machine Translation', in Proceedings of MT Summit XIV Workshop on Post-Editing Technology and Practice, Nice, 19-25. 
Moorkens, J. and S. O'Brien (2017) 'Assessing User Interface Needs of Post-Editors of Machine Translation', in D. Kenny (ed.) Human Issues in Translation Technology, London \& New York: Routledge, 109-30.

Morozov, E. (2013) To Save Everything, Click Here: The Folly of Technological Solutionism, New York: PublicAffairs.

O'Hagan, M. (2017) 'Deconstructing Translation Crowdsourcing with the Case of a Facebook Initiative: A Translation Network of Engineered Autonomy and Trust?', in D. Kenny (ed.) Human Issues in Translation Technology. London \& New York: Routledge, 25-44.

Olohan, M. (2011) 'Translators and Translation Technology: The Dance of Agency', Translation Studies 4(3): 342-57.

Olohan, M. (2017a) 'Technology, Translation and Society: A Constructivist, Critical Theory Approach', Target 29(2): 264-83.

Olohan, M. (2017b) 'Knowing in Translation Practice: A Practice-Theoretical Perspective', Translation Spaces 6(1): 160-81.

Olohan, M. and E. Davitti (2017) 'Dynamics of Trusting in Translation Project Management: Leaps of Faith and Balancing Acts', Journal of Contemporary Ethnography 46(4): 391-416.

Pedersen, D. (2017) 'Managing Transcreation Projects', Translation Spaces 6(1): 44-61.

Pickering, A. (1995) The Mangle of Practice: Time, Agency, and Science, Chicago, IL: University of Chicago Press.

Pickering, A. (2008) 'Preface', in A. Pickering, A. and K. Guzik (eds) The Mangle in Practice: Science, Society and Becoming, Durham, NC: Duke University Press, vii-xiv.

Pinch, T.J. and W.E. Bijker (1984) 'The Social Construction of Facts and Artefacts: Or How the Sociology of Science and the Sociology of Technology Might Benefit Each Other', Social Studies of Science 14(3): 399-441.

Risku, H. (2004) Translationsmanagement: Interkulturelle Fachkommunikation im Informationszeitalter, 1st ed., Tübingen: Gunter Narr.

Risku, H. (2009) Translationsmanagement: Interkulturelle Fachkommunikation im Informationszeitalter, 2nd ed., Tübingen: Gunter Narr.

Risku, H. (2016) 'Translatorisches Handeln: Anforderungen und Kompetenzen', in M. Kadrić and K. Kaindl (eds) Berufsziel Übersetzen und Dolmetschen: Grundlagen, Ausbildung, Arbeitsfelder. Tübingen: A. Francke Verlag, 39-62.

Risku, H., R. Rogl and J. Milosevic (2017) 'Translation Practice in the Field: Current Research on SocioCognitive Processes', Translation Spaces 6(1): 3-26.

Risku, H. and F. Windhager (2013) 'Extended Translation: A Sociocognitive Research Agenda', Target 25(1): 33-45.

Simeoni, D. (1998) 'The Pivotal Status of the Translator's Habitus', Target 10(1): 1-39.

Simeoni, D. (2007) 'Between Sociology and History: Method in Context and in Practice', in M. Wolf and A. Fukari (eds) Constructing a Sociology of Translation. Amsterdam \& Philadelphia: John Benjamins, 187-204.

Teixeira, C.S.C. and S. O'Brien (2017) 'Investigating the Cognitive Ergonomic Aspects of Translation Tools in a Workplace Setting', Translation Spaces 6(1): 79-103.

Tosoni, S. and T. Pinch (2017) Entanglements: Conversations on the Human Traces of Science, Technology, and Sound, Cambridge, MA: MIT Press.

Traweek, S. (1988) Beamtimes and Lifetimes: The World of High Energy Physicists, Cambridge, MA: Harvard University Press. 
UK Translator Survey (2017) London: European Commission Representation in the UK, Chartered Institute of Linguists, and Institute of Translation and Interpreting.

Vorderobermeier, G.M. (2014) Remapping Habitus in Translation Studies, Amsterdam: Rodopi.

Wajcman, J. (2000) 'Reflections on Gender and Technology Studies In What State Is the Art?', Social Studies of Science 30(3): 447-64.

Wolf, M. (2011) 'Mapping the Field: Sociological Perspectives on Translation', International Journal of the Sociology of Language 207: 1-28.

Wolf, M. and A. Fukari (eds) (2007) Constructing a Sociology of Translation, Amsterdam \& Philadelphia: John Benjamins. 